\title{
Percepção de noticiabilidade entre jornalistas, assessores de imprensa e leitores de jornais de Campo Grande $(M S)^{12}$
}

\author{
Marcos Paulo da Silva 3 \\ Mara Cristina de Morais Machado4
}

\begin{abstract}
Resumo
O artigo apresenta resultados de uma das etapas de uma investigação mais abrangente sobre o universo da seleção noticiosa e da narração jornalística em contextos regionais, notadamente no cenário de Mato Grosso do Sul. Do ponto de vista metodológico, segue-se um desenho estrutural análogo ao estudo de noticiabilidade desenvolvido por Shoemaker e Cohen (2006) em dez países de diferentes continentes. Para as finalidades específicas da presente discussão, volta-se o olhar em direção à percepção de noticiabilidade entre jornalistas, assessores de imprensa e leitores de jornais de Campo Grande (MS) a partir de inferências extraídas de exercícios de gatekeeping. Os resultados demonstram que não obstante exista concordância individual entre jornalistas e leitores na percepção de noticiabilidade, por outro lado identificam-se apenas fracas ou negativas relações entre as hierarquizações extraídas dos exercícios de gatekeeping e o conteúdo noticioso que integra o corpus de análise.
\end{abstract}

Palavras-chave: Jornalismo. Noticiabilidade. Mato Grosso do Sul. Gatekeeping.

\footnotetext{
1 A pesquisa contou com apoio de fomento pelos programas PIBIC/CNPq e PROCAD/CAPES.

2 Uma versão prévia do artigo foi apresentada no Grupo de Pesquisa Teorias do Jornalismo do 420. Congresso Brasileiro de Ciências da Comunicação, realizado de 2 a 7 de setembro de 2019 na Universidade Federal do Pará (UFPA), em Belém (PA).

3 Docente da Faculdade de Artes, Letras e Comunicação (FAALC) da Universidade Federal de Mato Grosso do Sul (UFMS). Doutor em Comunicação pela Universidade Metodista de São Paulo (UMESP), com estágio de doutorado-sanduíche (PDEE/CAPES) na Syracuse University (Nova lorque, Estados Unidos). Líder do Grupo de Pesquisa Cotidiano e Noticiabilidade (UFMS/CNPq). E-mail: marcos.paulo@ufms.br.

4 Jornalista graduada pela Universidade Federal de Mato Grosso do Sul (UFMS). Pesquisadora junto ao Grupo de Pesquisa Cotidiano e Noticiabilidade (UFMS/CNPq). E-mail: maracrismachado@hotmail.com.
}

Revista Pauta Geral-Estudos em Jornalismo, Ponta Grossa, v. 6, n. 2, p. 212-228, Jul/Dez, 2019. 


\section{Newsworthiness perception between journalists, press officers and newspaper readers from Campo Grande (MS)}

\section{Abstract}

The article presents results from one of the steps of a broader investigation about the universe of news selection and journalistic narration in regional contexts, notably in the case of Mato Grosso do Sul. From the methodological point of view, the research follows a structural design analogous to the newsworthiness study developed by Shoemaker and Cohen (2006) in ten countries of different continents. For the purposes of this article, the focus is on newsworthiness perception between journalists, press officers, and readers from Campo Grande (MS) newspapers based on inferences from gatekeeping exercises. The results show that although there is individual agreement between journalists and readers in the newsworthiness perception, on the other hand, it can be identified only weak or negative relations between the hierarchies from gatekeeping exercises and the news content that integrates the corpus of analysis.

Keywords: Journalism. Newsworthiness. Mato Grosso do Sul. Gatekeeping.

\section{Introdução}

A presente reflexão desenvolve-se em consonância com um conjunto mais amplo de discussões que se propõem a problematizar os multifacetados aspectos que configuram o universo da seleção noticiosa e da narração jornalística em contextos regionais (SILVA, 2014; 2017; SILVA, JERONYMO, 2018). O artigo localiza-se, nesse sentido, no escopo do projeto de pesquisa "Cotidiano e noticiabilidade na imprensa sulmato-grossense: interfaces entre jornalistas, assessores e público", inscrito junto à PróReitoria de Pesquisa e Pós-Graduação da Universidade Federal de Mato Grosso do Sul (PROPP/UFMS), cuja efetivação vincula-se também ao Grupo de Pesquisa Grupo de Pesquisa Cotidiano e Noticiabilidade, cadastrado no Conselho Nacional de Desenvolvimento Científico e Tecnológico $(\mathrm{CNPq})^{5}$. O estudo ainda integra o Projeto de

\footnotetext{
5 Num vértice estrutural, a pesquisa contempla quatro etapas nas quais são desenvolvidos estudos nas cidades mais populosas e com posições estratégicas nas diferentes mesorregiões instituídas pelo Instituto Brasileiro de Geografia e Estatística (IBGE) para o Estado; a saber: Campo Grande (Mesorregião do Centro-Norte), Ełapa 1; Corumbá
} 


\section{REVISTA PAUTA GERAL}

\section{ESTUDOS EM JORNALISMO}

DOI 10.5212/RevistaPautaGeral.v.6.i2.00013

Cooperação Acadêmica (PROCAD/CAPES) "Comunicação e mediações em contextos regionais: usos midiáticos, culturas e linguagens"'”, desenvolvido em parceria entre a Universidade de São Paulo (USP), a Universidade Federal do Rio Grande do Norte (UFRN) e a Universidade Federal de Mato Grosso do Sul (UFMS).

Do ponto de vista metodológico, sobretudo em relação aos aspectos referentes à coleta de dados empíricos, a pesquisa segue um desenho estrutural análogo ao levantamento de critérios de noticiabilidade desenvolvido por Shoemaker e Cohen (2006) em dez países de diferentes continentes - notadamente, a utilização de técnicas da análise de conteúdo ${ }^{6}$ para o estudo de jornais e de procedimentos qualitativos (grupos focais, entrevistas semiestruturadas e exercícios de gatekeeping). Para as finalidades específicas da presente discussão, em complementação a um estudo anterior calcado na interpretação das entrevistas semi-estruturadas (SILVA, 2018), volta-se o olhar em direção a um recorte singular: a percepção de noticiabilidade entre jornalistas, assessores e leitores de jornais de Campo Grande (MS) - extrato pertencente à fase qualitativa da Etapa 1 da pesquisa. Para tanto, vale-se dos resultados dos exercícios de gatekeeping realizados com os respectivos grupos de atores sociais na capital de Mato Grosso do Sul.

\section{As dimensões da noticiabilidade e o conceito de gatekeeping}

(Mesorregião dos Pantanais Sul-Mato-Grossenses), Ełapa 2; Três Lagoas (Mesorregião do Leste), Ełapa 3; e Dourados (Mesorregião do Sudoeste), Ełapa 4 (SILVA, 2014a).

6 Para a análise de conteúdo, foram selecionados os dois principais jornais de cada uma das cidades tomando como parâmetro para a escolha os seguintes itens: a) periodicidade; b) tiragem; c) perfil da publicação (se noticioso ou não); d) tempo de fundação do periódico. Com a intenção de evitar um enviesamento no processo de coleta dos dados empíricos, utilizou-se a amostragem aleatória sistemática por meio da técnica da semana composta. Foram classificados com base nas categorias de notícias propostas por Shoemaker e Cohen (2006) todos os itens noticiosos contidos nas edições selecionadas, privilegiando-se a vertente particularmente noticiosa do conteúdo jornalístico (modalidade caracterizada nos estudos teóricos do jornalismo como informativa) - em especial a vertente de itens noticiosos conhecida como factual (ou hard news na tradição norte-americana). Além da classificação fundamentada nas categorias temáticas elencadas por Shoemaker e Cohen (2006), cada item noticioso foi também classificado de acordo com sua dimensão (espaço físico) e com a posição hierárquica ocupada por ele no conjunto do conteúdo dos jornais (capa, primeira página de caderno e demais páginas). Finalmente, cada item recebeu uma codificação segundo a intensidade relativa às categorias de noticiabilidade utilizadas pelos autores: categorias de desvio (desvio estatístico, desvio normativo e desvio de mudança social) e categorias de significância social (significância econômica, significância política, significância cultural e significância pública). Para detalhes, ver: SILVA (2014a). 
A compreensão da complexidade do fenômeno da seleção noticiosa passa pela superação da sobreposição conceitual que se estabelece nos estudos em Jornalismo ao longo do século XX entre as concepções de noticiabilidade e de valor notícia. No contexto brasileiro, Gislene Silva (2005) é uma das primeiras pesquisadoras a enfatizar a necessidade de distinção entre os conceitos. Conforme os argumentos da autora brasileira, tal como também abordado em discussões anteriores (SILVA, 2014b; 2016), o equívoco se estabelece com base na opção metodológica de uma parcela significativa dos estudos sobre noticiabilidade de considerar inicialmente somente as características intrínsecas dos eventos, resultando posteriormente na inevitável verificação de que "a seleção prossegue no trajeto do tratamento dos fatos dentro da redação" (SILVA, 2005, p. 97). Desse modo, aspectos que dizem respeito a etapas específicas do fenômeno mais abrangente da noticiabilidade são colocadas em um mesmo patamar conceitual, levando duas ideias distintas - noticiabilidade e valor notícia - a receber a interpretação de equivalentes. Como diferenciação, por conseguinte, a autora sugere que os valoresnotícia devem ser sempre atrelados às "características do fato em si", enquanto a noticiabilidade é mais ampla e se estende no interior da redação, "quando é preciso não apenas escolher, mas hierarquizar" (SILVA, 2005, p. 98).

Em outro contexto, a pesquisadora norte-americana Pamela J. Shoemaker e o pesquisador israelense Akiba A. Cohen (2006) interpretam a noticiabilidade de uma maneira que também a diferencia das simples características primárias que particularizam um determinado evento. Entretanto, os autores compreendem a concepção como um constructo de ordem eminentemente cognitiva - por essa ótica, a noticiabilidade diz sempre respeito a julgamentos individuais - de jornalistas ou não - projetados sobre os acontecimentos do mundo fenomênico ("nós avaliamos continuamente a noticiabilidade das coisas em nosso mundo", frisam os autores). Além disso, Shoemaker e Cohen (2006, p. 342-343) admitem a impossibilidade de um evento atribuir a si próprio o estatuto de noticiável, pois, teoricamente, deverá haver sempre consenso entre as pessoas para que o fato possa receber aspectos de noticiabilidade suficientes para atingir os diferentes aspectos de suas realidades sociais.

A pesquisadora norte-americana e seu colega israelense constroem tais conclusões por meio dos resultados do estudo supracitado que congrega grupos focais e análise de conteúdo em dez países de diferentes continentes. De acordo com o 


\section{REVISTA PAUTA GERAL}

\section{ESTUDOS EM JORNALISMO}

DOI 10.5212/RevistaPautaGeral.v.6.i2.00013

levantamento, embora exista uma extensa concordância individual entre jornalistas e membros da audiência sobre a noticiabilidade de eventos dentro de suas respectivas realidades, por outro lado, são localizadas apenas fracas ou negativas relações entre as opiniões extraídas dos grupos focais (independentemente de suas categorias profissionais) e o conteúdo noticioso que de fato integra os veículos de comunicação nos países analisados. Logo, a noção de noticiabilidade não se ajusta automaticamente à ideia de proeminência na mídia (SHOEMAKER; COHEN, 2006, p.351-353).

Da mesma forma, a existência de distintas percepções sobre a noticiabilidade em diferentes recortes geográficos explica-se pela maneira como as próprias realidades sociais se diferenciam entre si. A noticiabilidade deve ser interpretada, assim, como a medida pela qual as informações sobre um evento tocam as várias partes que compõem a realidade social de uma pessoa; ou seja, baseado no modo como um acontecimento se conecta a uma determinada realidade ocorre o entendimento do mundo por parte das pessoas envolvidas nessa dinâmica interpretativa - possibilidade que concede também à noticiabilidade o estatuto de uma construção sociocultural. Ademais, tal como problematizado em reflexão anterior,

Em posição complementar, Shoemaker e Cohen (2006, p.335-337) defendem que as ideias de noticiabilidade e de notícia não podem ser interpretadas como noções equivalentes, uma vez que representam constructos teoricamente distintos: enquanto a noticiabilidade (...) é definida no nível individual de análise e leva em consideração a questão da saliência pessoal que um evento provoca, a notícia consiste em um artefato social complexo formatado por fatores como as rotinas profissionais da prática jornalística, as características organizacionais das empresas de comunicação e as influências das diferentes instituições sociais envolvidas no processo, além de variáveis macrossociais como valores culturais e ideologia. Em suma, significa reconhecer que qualquer pessoa, independentemente do estatuto de jornalista, pode atribuir juízos de noticiabilidade aos eventos que compõem sua realidade, mas somente os eventos que respondem aos critérios compartilhados no âmbito prática profissional do jornalismo serão admitidos fundamentalmente como notícias. Os chamados valores-notícia, nesse cenário, são vistos como os traços da noticiabilidade imbricados nas rotinas jornalísticas - ou seja, constituem os critérios de noticiabilidade utilizados no interior das rotinas profissionais para selecionar os fatos que serão efetivamente noticiados. (SILVA, 2016, p. 160-161).

A argumentação proporcionada por Shoemaker e Cohen (2006) após o estudo de abrangência internacional concede margem para a valorização de pesquisas sobre o tema da noticiabilidade com foco em realidades regionalizadas e para o realce das articulações 


\section{REVISTA PAUTA GERAL}

\section{ESTUDOS EM JORNALISMO}

DOI 10.5212/RevistaPautaGeral.v.6.i2.00013

entre as variáveis socioculturais pautadas pela regionalidade e os padrões culturais hegemônicos oriundos de contextos geográficos mais abrangentes.

O conceito de gatekeeping, por seu turno, diz respeito aos processos de seleção e de construção de itens noticiosos no interior das rotinas jornalísticas profissionais a partir de um conjunto de metáforas: portões, porteiros e canais, entre outras (WHITE, 1950). Os termos gatekeeping e comunicação foram relacionados pela primeira vez em 1947 por meio de um manuscrito não concluído do sociólogo Kurt Lewin sobre a modificação de hábitos alimentares na população estadounidense (SHOEMAKER; VOS, 2011). Discípulo de Lewin, o também sociólogo David Manning White (1950) foi o primeiro autor a fazer a apropriação do termo para a compreensão dos processos de seleção noticiosa. $O$ conjunto de metáforas trabalhado por Lewin resultou, por conseguinte, em um modelo para analisar o modo como ocorre a seleção e a razão que leva alguns itens a serem escolhidos e outros rejeitados nos procedimentos jornalísticos. Além disso, conforme explicitam Shoemaker e Vos (2011), a metáfora do gatekeeping também proporcionou uma estrutura para o estudo de outros procedimentos jornalísticos, como as dinâmicas de formatação e hierarquização das notícias.

A premissa básica da escola do gatekeeping é que as mensagens são geradas a partir de uma informação sobre eventos que tenha atravessado uma série de portões e tenha sofrido modificações ao longo do processo. Algumas dessas informações acabam indo parar na capa dos jornais, outras no meio de algum telejornal ou em uma página eletrônica da internet, e há ainda outras que nunca se transformam em notícia. Semelhantemente, um evento pode aparecer em algum veículo jornalístico, mas não em outros. Ou então determinada informação pode receber um grande destaque em um veículo e ser enterrada em outro (SHOEMAKER E VOS, 2011, p. 37).

Não por acaso, portanto, Shoemaker e Cohen (2006, p. 33), ao estruturarem o protocolo de estudo que utilizam no levantamento internacional, valem-se do escopo de um exercício de gatekeeping - aqui adapatado para um recorte regionalizado - para dimensionar a percepção de noticiabilidade entre agentes internos e externos do campo jornalístico.

\section{Exercício de gatekeeping}

Em sintonia com o protocolo de pesquisa proposto por Shoemaker e Cohen (2006) e adaptado para o contexto sul-mato-grossense por SILVA (2014a), foram 
aplicados os exercícios de gatekeeping em dez jornalistas e em oito leitores de jornais distribuídos em cinco grupos de análise $\left.{ }^{7}: 1\right)$ três jornalistas do jornal Correio do Estado, veículo de maior circulação em Mato Grosso do Sul e o único auditado pelo Instituto Verificador de Circulação ${ }^{8}$ (caracterizado na pesquisa como Veículo A); 2) três jornalistas do jornal $O$ Estado $M S$, veículo diário de segunda maior tiragem na capital estadual ${ }^{9}$ (caracterizado na pesquisa como Veículo $B)^{10}$; 3) quatro jornalistas de assessorias de imprensa com atuação na capital; 4) quatro leitores com nível de escolaridade básico e médio; e 5) quatro leitores com nível de escolaridade superior e pós-graduação. Com o propósito de obter um recorte com a devida diversidade de opiniões, as entrevistas atingiram diferentes níveis hierárquicos das empresas jornalísticas; isto é, de repórteres e pauteiros a subeditores e editores. Tal variação também ocorreu em relação às variáveis de gênero e de idade dos entrevistados:

- Veículo A: Jornalista 1, repórter júnior, sexo masculino; Jornalista 2, repórter sênior, sexo feminino; Jornalista 3, editora-chefe, sexo feminino.

- Veículo B: Jornalista 4, editor-chefe, sexo masculino; Jornalista 5, repórter, sexo masculino; Jornalista 6, pauteira/chefe de reportagem, sexo feminino.

Em relação às assessorias de comunicação, buscou-se um recorte que pudesse representar quatro áreas profissionais distintas: agências de comunicação, assessorias da área corporativa, assessorias de órgãos públicos e assessorias do terceiro setor (movimentos sociais e organizações não-governamentais). Quanto aos leitores de jornais, o primeiro grupo foi composto por quatro leitores com educação formal nos níveis fundamental e/ou médio: um vendedor, uma estudante de ensino médio, uma auxiliar de limpeza e um aposentado. O segundo grupo, por seu turno, foi composto por leitores com formação superior e/ou pós-graduação em suas áreas de atuação: um engenheiro civil,

\footnotetext{
7 Seguindo o cronograma quadrienal de pesquisa, as entrevistas e exercícios de gatekeeping na Ełapa 1 - Campo Grande (MS) foram aplicados entre março e agosto de 2015.

8 Tiragem diária auditada pelo IVC de 11,7 exemplares.

9 Tiragem diária autodeclarada de 6,8 mil exemplares.

10 Frisa-se que em etapa anterior da pesquisa os jornais mencionados já haviam sido objeto da análise de conteúdo a partir de um recorte empírico estruturado no modelo da semana construída. Ver: SILVA (2014a).
}

Revista Pauta Geral-Estudos em Jornalismo, Ponta Grossa, v. 6, n. 2, p. 212-228, Jul/Dez, 2019 


\section{REVISTA PAUTA GERAL}

\section{ESTUDOS EM JORNALISMO}

DOI 10.5212/RevistaPautaGeral.v.6.i2.00013

uma professora da área de Letras, um advogado com atuação também como professor universitário e um capelão com atuação como professor de Bioética. Buscou-se, dessa forma, um equilíbrio entre idade, gênero e ocupação profissional em ambos os conjuntos de atores selecionados. A seleção aleatória dos leitores e a execução do protocolo de pesquisa foram realizadas no âmbito do estudo por pesquisadores em nível de Iniciação Científica (bolsistas PIBIC/CNPq e PROCAD/CAPES).

No desenvolvimento do exercício de gatekeeping, seguiu-se aplicação análoga dos passos estabelecidos no protocolo de Shoemaker e Cohen (2006) em dez países:

Após a conclusão da análise de conteúdo em cada jornal, os índices de proeminência dos itens noticiosos foram previamente calculados com base na dimensão recebida nos jornais (incluindo tanto o conteúdo verbal como visual) e em suas posições em cada veículo. (...) Para cada data, dez itens foram identificados com base no ranqueamento de seus índices de proeminência a partir do mais destacado para o de menor pontuação. (...) Três listas de dez itens foram elaboradas, sendo que o título e a linha fina (se existente) de cada item foram impressos em cartões com uma chamada por ficha, (...) nenhuma outra informação aparecia nos cartões. (SHOEMAKER, COHEN, 2006, p.33, tradução nossa).

Por índice de proeminência, tal como na proposta de Shoemaker e Cohen (2006), entende-se o resultado da multiplicação entre a dimensão dos itens noticiosos (em centímetros quadrados) e a codificação de sua posição hierárquica (capa, pontuação 3; primeira página de caderno, pontuação 2; e demais páginas, pontuação 1). Na adaptação do protocolo de pesquisa para a realidade regionalizada de Mato Grosso do Sul, no entanto, elaborou-se uma única lista de dez enunciados de itens noticiosos extraídos aleatoriamente das notícias codificadas e categorizadas nos dois jornais estudados na fase da análise de conteúdo, a saber por ordem decrescente de proeminência:

1. "Mulher tem perna amputada e se diz vítima de erro médico" (O Estado MS, 14/05/2013, terça-feira, página B1, Saúde), dimensão de 973,5 centímetros quadrados, índice de proeminência 2920,5.

2. "Copa das Confederações: Mexicanos confiantes no título" (Correio do Estado, 07/06/2013, sexta-feira, página 18, Esportes), dimensão 1254 centímetros quadrados, índice de proeminência 2508.

3. "Custo da cesta de produtos entre os supermercados varia em 9,61\% na Capital" (O Estado MS, 15/16/2013, sábado, página A8, Economia), dimensão 776,88 centímetros quadrados, índice de proeminência 1553,76.

4. "Protesto contra tarifa de ônibus teve 235 detidos em São Paulo" (O Estado MS, 15/06/2013, sábado, página B8, Transporte), dimensão 758,5 centímetros quadrados, índice de proeminência 1517. 


\title{
REVISTA PAUTA GERAL
}

\section{ESTUDOS EM JORNALISMO}

DOI 10.5212/RevistaPautaGeral.v.6.i2.00013

5. "Brasileiro conquista 'o melhor emprego do mundo'" (Correio do Estado, 23/06/2013, Domingo, página 8, Entretenimento/Relações trabalhistas), dimensão 958,75 centímetros quadrados, índice de proeminência 958,75.

6. "Câmara exige pedido de perdão de Bernal [ex-prefeito de Campo Grande]" (Correio do Estado, 07/06/2013, sexta-feira, capa, Política), dimensão 253 centímetros quadrados, índice de proeminência 759.

7. "Aos 32 anos, homem morre com sintomas de gripe suína na capital" (Correio do Estado, 30/05/2013, quinta-feira, página 9A, Saúde), dimensão 754 centímetros quadrados, índice de proeminência 754.

8. "Papa Francisco admite que até ele tem muitos pecados" (Correio do Estado, 30/05/2013, quinta-feira, página 11A, Interesse Humano/Outros), dimensão 90,25 centímetros quadrados, índice de proeminência 270,75.

9. "Médico denuncia 25 mortes de bebês em hospital do Pará" (O Estado MS, 15/06/2013, sábado, página B8, Desastres/Acidentes/Epidemias), dimensão 65,88 centímetros quadrados, índice de proeminência 131,76.

10. "Sobe para 610 os mortos no desabamento em Bangladesh" (O Estado MS, 06/06/2013, segunda-feira, página A6, Desastres/Acidentes/Epidemias), dimensão 63,5 centímetros quadrados, índice de proeminência 127.

Após aplicação de uma entrevista semi-estruturada (SILVA, 2017), todos participantes do exercício de gatekeeping foram orientados a hierarquizar as dez fichas (sem as informações de origem, dimensão e proeminência), a exemplo do protocolo da pesquisa internacional:

\begin{abstract}
Depois que a discussão qualitativa foi completada, o grupo moderador entregou a cada participante um grupo de dez cartões oriundos de uma das três datas selecionadas. Os participantes receberam a orientação de que todos aqueles itens teriam sido extraídos de um jornal local em um dia aleatório, sendo solicitado a eles que organizassem os cartões segundo a ordem na qual, tal como fossem editores do jornal, hierarquizariam para a publicação, basendo-se no grau de importância que pessoalmente atribuiam aos assuntos de cada item. Em outras palavras, solicitou-se dos participantes a indicação, em seus pontos de vista, daquilo que era mais interessante/noticiável (newsworthy) e que mereceria prioridade máxima, bem como, na sequência, a segunda prioridade, e assim por diante para todos os dez itens. (SHOEMAKER, COHEN, 2006, p.33, tradução nossa).
\end{abstract}

A ordem de classificação dos enunciados acima descritos foi disposta em tabelas por grupo de aplicação do exercício:

Tabela 1 - Ordem de classificação atribuída por jornalistas do Veículo $A$

\begin{tabular}{|c|c|c|c|c|}
\hline $\begin{array}{c}\text { Ordem do } \\
\text { enunciado }\end{array}$ & $\begin{array}{c}\text { Índice de } \\
\text { proeminência }\end{array}$ & Jornalista 01 & Jornalista 02 & Jornalista 03 \\
\hline $\mathbf{1}$ & 2920,5 & 6 & 6 & 8 \\
\hline $\mathbf{2}$ & 2508 & 8 & 9 & 10 \\
\hline
\end{tabular}

Revista Pauta Geral-Estudos em Jornalismo, Ponta Grossa, v. 6, n. 2, p. 212-228, Jul/Dez, 2019. 


\section{REVISTA PAUTA GERAL}

\section{ESTUDOS EM JORNALISMO}

DOI 10.5212/RevistaPautaGeral.v.6.i2.00013

\begin{tabular}{|c|c|c|c|c|}
\hline $\mathbf{3}$ & 1553,76 & 2 & 4 & 2 \\
\hline $\mathbf{4}$ & 1517 & 4 & 3 & 4 \\
\hline $\mathbf{5}$ & 958,75 & 10 & 2 & 6 \\
\hline $\mathbf{6}$ & 759 & 1 & 5 & 3 \\
\hline $\mathbf{7}$ & 754 & 5 & 7 & 1 \\
\hline $\mathbf{8}$ & 270,75 & 9 & 10 & 5 \\
\hline $\mathbf{9}$ & 131,76 & 3 & 1 & 7 \\
\hline $\mathbf{1 0}$ & 127 & 7 & 8 & 9 \\
\hline
\end{tabular}

(Fonte: Tabela elaborada pelos autores para efeitos da pesquisa)

Tabela 2 - Ordem de classificação atribuída por jornalistas do Veículo $B$

\begin{tabular}{|c|c|c|c|c|}
\hline $\begin{array}{c}\text { Ordem do } \\
\text { enunciado }\end{array}$ & Proeminência & Jornalista 04 & Jornalista 05 & Jornalista06 \\
\hline $\mathbf{1}$ & 2920,5 & 3 & 1 & 3 \\
\hline $\mathbf{2}$ & 2508 & 9 & 7 & 9 \\
\hline $\mathbf{3}$ & 1553,76 & 2 & 4 & 2 \\
\hline $\mathbf{4}$ & 1517 & 6 & 9 & 6 \\
\hline $\mathbf{5}$ & 958,75 & 10 & 6 & 10 \\
\hline $\mathbf{6}$ & 759 & 4 & 3 & 4 \\
\hline $\mathbf{7}$ & 754 & 1 & 2 & 1 \\
\hline $\mathbf{8}$ & 270,75 & 7 & 5 & 8 \\
\hline $\mathbf{9}$ & 131,76 & 5 & 8 & 5 \\
\hline $\mathbf{1 0}$ & 127 & 8 & 10 & 7 \\
\hline
\end{tabular}

(Fonte: Tabela elaborada pelos autores para efeitos da pesquisa)

Tabela 3 - Ordem de classificação atribuída por assessores de imprensa

\begin{tabular}{|c|c|c|c|c|c|}
\hline $\begin{array}{c}\text { Ordem do } \\
\text { enunciado }\end{array}$ & Proeminência & Jorn. 07 & Jorn. 08 & Jorn. 09 & Jorn. 10 \\
\hline $\mathbf{1}$ & 2920,5 & 6 & 5 & 3 & 6 \\
\hline $\mathbf{2}$ & 2508 & 9 & 10 & 7 & 10 \\
\hline $\mathbf{3}$ & 1553,76 & 4 & 7 & 5 & 5 \\
\hline $\mathbf{4}$ & 1517 & 8 & 3 & 8 & 4 \\
\hline $\mathbf{5}$ & 958,75 & 3 & 4 & 4 & 8 \\
\hline $\mathbf{6}$ & 759 & 2 & 9 & 10 & 7 \\
\hline $\mathbf{7}$ & 754 & 5 & 6 & 1 & 2 \\
\hline $\mathbf{8}$ & 270,75 & 10 & 8 & 6 & 9 \\
\hline $\mathbf{9}$ & 131,76 & 1 & 2 & 2 & 1 \\
\hline $\mathbf{1 0}$ & 127 & 7 & 1 & 9 & 3 \\
\hline
\end{tabular}

(Fonte: Tabela elaborada pelos autores para efeitos da pesquisa)

Tabela 4 - Ordem de classificação atribuída por leitores de formação em nível fundamental e nível médio

\begin{tabular}{|c|c|c|c|c|c|}
\hline $\begin{array}{c}\text { Ordem do } \\
\text { enunciado }\end{array}$ & Proeminência & Leitor 01 & Leitor 02 & Leitor 03 & Leitor 04 \\
\hline $\mathbf{1}$ & 2920,5 & 3 & 4 & 7 & 7 \\
\hline $\mathbf{2}$ & 2508 & 9 & 10 & 9 & 10 \\
\hline $\mathbf{3}$ & 1553,76 & 6 & 7 & 3 & 2 \\
\hline
\end{tabular}

Revista Pauta Geral-Estudos em Jornalismo, Ponta Grossa, v. 6, n. 2, p. 212-228, Jul/Dez, 2019. 
REVISTA PAUTA GERAL

\section{ESTUDOS EM JORNALISMO}

DOI 10.5212/RevistaPautaGeral.v.6.i2.00013

\begin{tabular}{|c|c|c|c|c|c|}
\hline $\mathbf{4}$ & 1517 & 10 & 6 & 4 & 5 \\
\hline $\mathbf{5}$ & 958,75 & 1 & 5 & 6 & 8 \\
\hline $\mathbf{6}$ & 759 & 2 & 9 & 10 & 1 \\
\hline $\mathbf{7}$ & 754 & 4 & 8 & 8 & 9 \\
\hline $\mathbf{8}$ & 270,75 & 8 & 3 & 1 & 3 \\
\hline $\mathbf{9}$ & 131,76 & 5 & 2 & 2 & 4 \\
\hline $\mathbf{1 0}$ & 127 & 7 & 1 & 5 & 6 \\
\hline
\end{tabular}

(Fonte: Tabela elaborada pelos autores para efeitos da pesquisa)

Tabela 5 - Ordem de classificação atribuída por leitores de formação em nível superior e pós-graduação

\begin{tabular}{|c|c|c|c|c|c|}
\hline $\begin{array}{c}\text { Ordem do } \\
\text { enunciado }\end{array}$ & Proeminência & Leitor 01 & Leitor 02 & Leitor 03 & Leitor 04 \\
\hline $\mathbf{1}$ & 2920,5 & 6 & 8 & 1 & 1 \\
\hline $\mathbf{2}$ & 2508 & 10 & 9 & 4 & 9 \\
\hline $\mathbf{3}$ & 1553,76 & 8 & 1 & 9 & 4 \\
\hline $\mathbf{4}$ & 1517 & 3 & 3 & 7 & 5 \\
\hline $\mathbf{5}$ & 958,75 & 9 & 7 & 2 & 6 \\
\hline $\mathbf{6}$ & 759 & 4 & 2 & 6 & 10 \\
\hline $\mathbf{7}$ & 754 & 5 & 4 & 5 & 3 \\
\hline $\mathbf{8}$ & 270,75 & 2 & 10 & 3 & 7 \\
\hline $\mathbf{9}$ & 131,76 & 7 & 5 & 10 & 2 \\
\hline $\mathbf{1 0}$ & 127 & 1 & 6 & 8 & 6 \\
\hline
\end{tabular}

(Fonte: Tabela elaborada pelos autores para efeitos da pesquisa)

\section{A noticiabilidade como categoria cognitiva: inferências}

A análise de conteúdo das tabelas elaboradas a partir do exercício de gatekeeping possibilita uma série de inferências sobre a natureza cognitiva dos processos de noticiabilidade no recorte estudado. Primeiramente, mostra-se pertinente sublinhar que das 180 posições de hierarquização compreendidas nas tabelas - ou seja, os dez itens noticiosos elencados por cada um dos 18 atores sociais pesquisados - apenas sete (o que equivale a $3,9 \%$ ) tiveram equivalência exata entre a percepção dos participantes e a ordem oriunda dos índices de proeminência (isto é, a ordem de proeminência na qual, em tese, os itens selecionados efetivamente aparecem nos jornais). O dado não se apresenta estatisticamente relevante e mostra-se ainda mais restrito quando o recorte se estabelece apenas entre os grupos de leitores (Tabelas 4 e 5$)$ : cinco leitores (2,8\% do total das posições), sendo três do grupo de formação em nível superior e pós-graduação e dois do grupo de formação em nível fundamental e médio. 


\section{REVISTA PAUTA GERAL}

\section{ESTUDOS EM JORNALISMO}

DOI 10.5212/RevistaPautaGeral.v.6.i2.00013

Por outro lado, no que tange a disparidade absoluta entre os índices de proeminência e a percepção de noticiabilidade dos atores sociais participantes da pesquisa - ou seja, nos casos em que os entrevistados atribuíram a menor relevância (posição 10 no exercício de gatekeeping) ao item indexado com maior proeminência (posição 1 na listagem de itens noticiosos) ou vice-versa -, o resultado também não se mostra estatisticamente expressivo: são apenas três casos (ou 1,7\% do total). Entretanto, a proporção salta para $11,7 \%$ (ou 21 casos) quando são considerados os casos que se aproximam da disparidade absoluta com diferença de apenas uma posição. Tal recorte envolve $14(77,8 \%)$ dos 18 atores sociais participantes da pesquisa, sendo a totalidade dos integrantes do grupo de assessores de imprensa e de leitores com formação em nível ensino fundamental e médio e $75 \%$ dos leitores com formação em nível superior e pósgraduação. Denota-se, portanto, que a disparidade entre os índices de proeminência e a percepção de noticiabilidade por parte dos participantes da pesquisa é significativamente expressiva.

Chama particularmente atenção o fato de que o enunciado que ocupa a sexta colocação em termos de proeminência - "Câmara exige pedido de perdão de Bernal [exprefeito de Campo Grande]" (Correio do Estado, 07/06/2013, sexta-feira, capa, Política), dimensão de 253 centímetros quadrados, índice de proeminência 759 - foi considerado o mais relevante por um terço (seis) dos 18 entrevistados, sendo cinco participantes integrantes dos grupos dos jornalistas profissionais (dois deles entre os assessores de imprensa), muito embora curiosamente não tenha ocorrido nenhum caso entre os jornalistas do Veículo $B$. O resultado denota que pautas políticas locais - sobretudo se o veículo particularmente apresentar tal vertente informativa - encontram aderência na percepção de noticiabilidade dos jornalistas profissionais, porém não necessariamente entre os grupos de leitores.

Em relação à linearidade apresentada na comparação entre os entrevistados, constata-se que em 14 casos (28\% num total de 50 linhas, sendo 10 linhas de hierarquização por cada um dos cinco grupos pesquisados) a diferença entre as posições revela a distância máxima de duas posições. São 12 casos entre jornalistas $(40 \%$ entre 30 linhas no total) e 2 casos entre leitores (10\% no total de 20 linhas), o que também se mostra estatisticamente relevante. Nesse sentido, é salutar a constatação de que dois jornalistas do grupo de profissionais do Veículo $B$ (Jornalista 4, editor-chefe, sexo 


\section{REVISTA PAUTA GERAL}

\section{ESTUDOS EM JORNALISMO}

DOI 10.5212/RevistaPautaGeral.v.6.i2.00013

masculino; e Jornalista 6, pauteira/chefe de reportagem, sexo feminino), não por acaso ocupantes de posições administrativas de edição, apresentam resultados - isto é, percepção de noticiabilidade - praticamente idênticos. No mais, quando se considera a diferença máxima de distância de três posições, a linearidade entre os atores participantes da pesquisa sobre para 22 casos (44\% num total de 50 linhas), sendo 19 casos entre jornalistas $(63,3 \%$ num total de 30 linhas), todavia apenas 3 casos entre leitores (15\% do total de 20 linhas).

Pode-se inferir, nesse cenário, a existência de um maior compartilhamento de valores simbólicos entre os agentes do campo jornalístico - percepção de noticiabilidade que se manifesta na linearidade das respostas. No universo dos leitores, porém, a linearidade mostra-se mais escassa, de onde se pode inferior que, embora os consumidores de notícias estejam agrupados por níveis de formação (um grupo de formação fundamental e média e outro de formação superior e pós-graduação), as áreas de atuação e formação são bastante díspares, remetendo a percepções de noticiabilidade também heterogêneas. Aqui, uma vez mais, sublinha-se a compreensão da noticiabilidade como um constructo de natureza eminentemente cognitiva.

Ao final do exercício, considerando tanto a hierarquização geral dos itens noticiosos oriunda do conjunto dos cinco grupos quanto a hierarquização no interior de cada grupo, a ordem de posicionamento dos enunciados destoa-se da ordem estabelecida pelos índices de proeminência. A ordem a partir do conjunto dos grupos configura-se da seguinte maneira:

1. "Médico denuncia 25 mortes de bebês em hospital do Pará" (O Estado MS, 15/06/2013, sábado, página B8, Desastres/Acidentes/Epidemias), dimensão 65,88 centímetros quadrados, índice de proeminência 131,76 (posição original 9).

2. Aos 32 anos, homem morre com sintomas de gripe suína na capital" (Correio do Estado, 30/05/2013, quinta-feira, página 9A, Saúde), dimensão 754 centímetros quadrados, índice de proeminência 754 (posição original 7).

3. "Custo da cesta de produtos entre os supermercados varia em 9,61\% na Capital" (O Estado MS, 15/16/2013, sábado, página A8, Economia), dimensão 776,88 centímetros quadrados, índice de proeminência 1553,76 (posição original 3).

4. "Mulher tem perna amputada e se diz vítima de erro médico" (O Estado MS, 14/05/2013, terça-feira, página B1, Saúde), dimensão de 973,5 centímetros quadrados, índice de proeminência 2920,5 (posição original 1).

5. "Câmara exige pedido de perdão de Bernal [ex-prefeito de Campo Grande]" (Correio do Estado, 07/06/2013, sexta-feira, capa, Política), dimensão 253 centímetros quadrados, índice de proeminência 759 (posição original 6). 


\section{REVISTA PAUTA GERAL}

\section{ESTUDOS EM JORNALISMO}

DOI 10.5212/RevistaPautaGeral.v.6.i2.00013

6. "Protesto contra tarifa de ônibus teve 235 detidos em São Paulo" (O Estado MS, 15/06/2013, sábado, página B8, Transporte), dimensão 758,5 centímetros quadrados, índice de proeminência 1517 (posição original 4).

7. "Brasileiro conquista 'o melhor emprego do mundo'" (Correio do Estado, 23/06/2013, Domingo, página 8, Relações trabalhistas), dimensão 958,75 centímetros quadrados, índice de proeminência 958,75 (posição original 5).

8. "Sobe para 610 os mortos no desabamento em Bangladesh" (O Estado MS, 06/06/2013, segunda-feira, página A6, Desastres/Acidentes/Epidemias), dimensão 63,5 centímetros quadrados, índice de proeminência 127 (posição original 10).

9. "Papa Francisco admite que até ele tem muitos pecados" (Correio do Estado, 30/05/2013, quinta-feira, página 11A, Interesse Humano/Outros), dimensão 90,25 centímetros quadrados, índice de proeminência 270,75 (posição original 8).

10. "Copa das Confederações: Mexicanos confiantes no título" (Correio do Estado, 07/06/2013, sexta-feira, página 18, Esportes), dimensão 1254 centímetros quadrados, índice de proeminência 2508 (posição original 2).

O levantamento evidencia uma concordância significativa por parte dos atores sociais participantes em elementos específicos, a exemplo da percepção de noticiabilidade inversamente proporcional do enunciado que possui o segundo maior índice de proeminência - "Copa das Confederações: Mexicanos confiantes no título" (Correio do Estado, 07/06/2013, sexta-feira, página 18, Esportes) -, hierarquizado na última posição em quatro grupos (Jornalistas do Veículo A; Assessores de Imprensa; Leitores com nível formação fundamental e médio; e Leitores com nível de formação superior e pós-graduação) e na penúltima posição em um grupo (Jornalistas do Veículo $B)$. Infere-se também que os enunciados com maior percepção de noticiabilidade em termos de relevância dizem respeito a questões de saúde de pessoas anônimas (o que inclui tragédias médicas) e de economia popular, assuntos que denotam uma proximidade com elementos da vida cotidiana (SILVA, 2017). Por outro lado, o item classificado como mais relevante na classificação geral de percepção de noticiabilidade - "Médico denuncia 25 mortes de bebês em hospital do Pará" (O Estado MS, 15/06/2013, sábado, página B8, Desastres/Acidentes/Epidemias) - relativiza o critério da proximidade geográfica como fator preponderante (FERNANDES, 2013). Ainda assim, faz-se importante ressaltar que em sintonia com a premissa da proximidade geográfica - os três últimos enunciados elencados pelos entrevistados fazem de alguma forma referência ao contexto internacional, um deles envolvendo uma celebridade religiosa, mas com protagonismo midiático - "Papa Francisco admite que até ele tem muitos pecados" (Correio do Estado, 30/05/2013, quinta-feira, página 11A, Interesse Humano/Outros). 


\section{REVISTA PAUTA GERAL}

\section{ESTUDOS EM JORNALISMO}

DOI 10.5212/RevistaPautaGeral.v.6.i2.00013

\section{Considerações finais}

A aplicação do exercício de gatekeeping junto aos grupos de entrevistados participantes da Etapa 1 - Campo Grande (MS) da pesquisa "[nome ocultado para avaliação cega]" resulta em um terreno fértil para o desenvolvimento de interpretações sobre a natureza cognitiva da noticiabilidade em recortes regionalizados. Em grande medida, os resultados extraídos das inferências encontram ressonância nas interfaces das categorias de noticiabilidade oriundas das entrevistas semi-estruturadas realizadas com os mesmos grupos de atores sociais que foram anteriormente estudadas sob a perspectiva do conceito de vida cotidiana (SILVA, 2017). Nesse sentido,

No que tange à própria definição de notícia pelos atores sociais estudados - de onde é possível abstrair e sistematizar "categorias de noticiabilidade" - encontrase, por exemplo, uma bastante emblemática aproximação nas perspectivas dos entrevistados, sejam eles jornalistas de redação (de diferentes idades, gêneros e funções), assessores de imprensa (de organizações de diferentes naturezas) ou leitores de nível de escolaridade básico ou superior (de diferentes idades, profissões e gêneros). "Inesperado", "surpresa", "novidade", "importância", proximidade", "relevância", "prestação de serviço", "interesse público" e "notoriedade dos envolvidos": em certa medida, as categorias mencionadas se sobrepõem não somente no interior das respostas dos diferentes grupos pesquisados (justaposição que por si só já merece problematização), mas também entre as categorias históricas de valores noticiosos sistematizados por autores de diferentes épocas. (SILVA, 2017, p.94).

Os resultados também são consonantes com as inferências realizadas por Shoemaker e Cohen (2006) no levantamento internacional sobre noticiabilidade que procurou mensurar as influências de natureza sociocultural em dez países de diferentes continentes. De acordo os autores, a noção de noticiabilidade não se ajusta automaticamente à ideia de proeminência na mídia (SHOEMAKER; COHEN, 2006, p.351353), o que pode inclusive remeter, muitas vezes, à configuração de vetores em posições inversamente proporcionais - tal como demonstrado nos resultados do exercício de gatekeeping aqui analisado. A exemplo do estudo conduzido pela pesquisadora norteamericana e por seu colega israelense, o recorte realizado na capital sul-mato-grossense demonstra que não obstante exista concordância individual entre jornalistas e membros dos grupos de leitores na percepção de noticiabilidade de acontecimentos que perpassam suas vidas cotidianas, por outro lado identificam-se apenas fracas ou negativas relações 


\section{REVISTA PAUTA GERAL}

\section{ESTUDOS EM JORNALISMO}

DOI 10.5212/RevistaPautaGeral.v.6.i2.00013

entre as hierarquizações extraídas dos exercícios de gatekeeping nos diferentes grupos (independentemente de suas categorias profissionais) e o conteúdo noticioso que de fato integra os veículos de comunicação constituintes do corpus de análise.

Os chamados valores-notícia, por seu turno, são aqui caracterizados como os traços da noticiabilidade diretamente imbricados nas rotinas jornalísticas - ou seja, constituem os critérios de noticiabilidade utilizados no interior das rotinas profissionais para selecionar os fatos que serão efetivamente noticiados. No interior desta perspectiva, uma vez mais encontra-se ressonância entre os resultados do exercício de gatekeeping sobretudo aqueles localizados nos três grupos compostos por profissionais jornalistas - e as constatações sobre valores profissionais anteriormente identificados a partir das entrevistas semi-estruturadas (SILVA, 2017).

Conclui-se assim, em sintonia com Shoemaker e Cohen (2006), que a noticiabilidade deve ser interpretada como a medida pela qual as informações sobre um acontecimento perpassam as multifacetadas relações sociais que constituem a vida cotidiana num determinado recorte geográfico e sociocultural; isto é, baseado no modo como um acontecimento se conecta a uma determinada realidade social desvela-se a compreensão do mundo por parte das pessoas envolvidas nessa dinâmica interpretativa. Noticiabilidade e proeminência jornalística, portanto, constituem constructos bastante distintos: enquanto a primeira estrutura-se em aspectos cognitivos, a segunda remete à produção e hierarquização de artefatos culturais de base industrial decorrentes de diferentes níveis de influência (SHOEMAKER, REESE, 1996) - as notícias.

\section{Referências}

FERNANDES, Mario Luiz. A proximidade como valor-notícia na imprensa do interior. In: ASSIS, Francisco de (Org.). Imprensa do interior: conceitos e contextos. 1ed. Chapecó: Argos, 2013, v. 4, p. 103-136.

SHOEMAKER, Pamela J. e REESE, Stephen D. Mediating the message: theories of influences of mass media content. 2. ed. White Plains (NY): Longman, 1996.

SHOEMAKER, Pamela J. e COHEN, Akiba. News around the world: Practitioners, Content, and the Public. New York: Routledge, 2006.

SHOEMAKER, Pamela J., VOS, Tim P. Teoria do Gatekeeping: construção e seleção da notícia. Porto Alegre: Editora Penso, 2009. 


\section{REVISTA PAUTA GERAL}

\section{ESTUDOS EM JORNALISMO}

DOI 10.5212/RevistaPautaGeral.v.6.i2.00013

SILVA, Gislene. Para pensar a noticiabilidade. Revista Estudos em Jornalismo e Mídia. Universidade Federal de Santa Catarina, v. 2, n. 1, 2005.

SILVA, Marcos Paulo da. Cotidiano e Noticiabilidade na imprensa sul-matogrossense: interfaces entre jornalistas, assessores e público. In: Anais do XXXVII Congresso Brasileiro de Ciências da Comunicação. Foz do Iguaçu (SP): INTERCOM, 2014a.

SILVA, Marcos Paulo da. Por um percurso da noticiabilidade à estética jornalística. In: LUVIZOTTO, Caroline Kraus; LOSNAK, Célio José; ROTHBERG, Danilo (Orgs.). Mídia e Sociedade em Transformação. 1ed. São Paulo (SP): Cultura Acadêmica, 2016, v. 1, p. 149-168.

SILVA, Marcos Paulo da. Seleção noticiosa, critérios de noticiabilidade e valores-notícia. In: SILVA, Gislene; SILVA, Marcos Paulo da; FERNANDES, Mario Luiz (Orgs.). Critérios de Noticiabilidade: problemas conceituais e aplicações. 1ed.Florianópolis (SC): Editora Insular, 2014b, v. 1, p. 71-83.

SILVA, Marcos Paulo da. Da narração do cotidiano ao cotidiano da narração: a noticiabilidade como categoria cognitiva no jornalismo de Campo Grande (MS). Revista Comunicação Midiática, v. 12, p. 86-100, 2017.

SILVA, Marcos Paulo da; JERONYMO, Raquel de Souza. A construção cultural de critérios noticiosos em contextos regionais: reflexões teórico-metodológicas a partir dos jornais de Corumbá (MS). Revista Observatório, v. 4, p. 367-388, 2018.

WHITE, David Manning. The gatekeeper: a case study in the selection of news. Journalism Quarterly, n.27, 1950. 